\title{
ÉTICA, TÉCNICA E PROGRESSO CIENTÍFICO: UMA ANÁLISE DO PRINCÍPIO DA RESPONSABILIDADE EM HANS JONAS
}

\author{
Marcos Alexandre Alves ${ }^{1}$ \\ Centro Universitário Franciscano (UNIFRA) \\ (D) https://orcid.org/0000-0002-5271-0624 \\ Neimir Paulo Mentges ${ }^{2}$ \\ Centro Universitário Franciscano (UNIFRA)
}

\section{RESUMO:}

O presente artigo examina a leitura de Hans Jonas sobre o impacto das novas tecnologias nas vidas humana e extra-humana. Destaca, de modo particular, que as novas tecnologias conferiram um poder desmedido ao homem, que não só trazem consequências boas, mas também desastrosas, podendo inclusive acarretar a extinção da vida presente e futura. Ratifica que esse significativo aumento no conhecimento técnico, infelizmente não foi proporcional ao aumento da sabedoria humana. A intenção consiste em apresentar, desde a compreensão de Hans Jonas, a proposta de revisão dos patamares éticos vigentes ao longo da tradição filosófica ocidental; elucidar as principais características da técnica moderna; mostrar as insuficiências da ética tradicional diante dos problemas emergentes no mundo contemporâneo; circunscrever como surge e se constitui o princípio ético da responsabilidade e mostrar em que medida o progresso científico demanda prudência ética. Portanto, defende-se que a ética jonasiana ultrapassa a relação antropocêntrica, preconizando uma ética bio-cosmocêntrica que engloba o extra-humano, tendo em vista o desenvolvimento da consciência ética e a responsabilidade do homem para com o presente e futuro da vida no planeta.

\footnotetext{
${ }^{1}$ Professor Adjunto do Curso de Filosofia e do Mestrado em Ensino de Humanidades e Linguagens - Centro Universitário Franciscano - UNIFRA - Brasil. E-mail: maralexalves@gmail.com

${ }^{2}$ Licenciado em Filosofia - Centro Universitário Franciscano - UNIFRA - Brasil. neimirmentges@gmail.com

Ética, técnica e progresso científico: uma análise do princípio da responsabilidade em Hans Jonas - Marcos Alexandre Alves; Neimir Paulo Mentges
}

Griot : Revista de Filosofia, Amargosa, Bahia - Brasil, v.15, n.1, p.111-127, junho/2017 
Palavras-chave: Ética; Técnica; Princípio Responsabilidade; Heurística do Medo.

\title{
ETHICS, TECHNIQUE AND SCIENTIFIC PROGRESS: AN ANALYSIS OF THE PRINCIPLE OF RESPONSIBILITY IN HANS JONAS
}

\begin{abstract}
:
This paper examines the reading of Hans Jonas about the impact of new technologies on human and extra-humanlife. He highlights, in particular, that new technologies have assumed an excessive power to the man, who bringsboth good and disastrous consequences, which may even lead to the extinction of the present and future life. He confirms that this significant increase in technical knowledge. Unfortunately, that was not proportional to the increase of human wisdom. So, our intention is to present, according to the understanding of Hans Jonas, the proposed review of the prevailing ethical levels along the western philosophical tradition; elucidating the main features of modern technology; presenting the shortcomings of traditional ethics before emerging problems in the contemporary world; circumscribing how ethical principle of responsibility emerges and showing how extent scientific progress demands ethical prudence. Therefore, we support the idea that the ethics of Hans Jonas goes beyond the anthropocentric relationship, promoting bio-cosmocentric ethics that includes the extra-human, considering the development of ethical awareness and the responsibility of man to the present and future of life on the planet.
\end{abstract}

KEYWORDS: Éthics; Technique; Imperative of Responsibility; Heuristics of fear.

Introdução

A filosofia de Hans Jonas está fortemente imbuída da sua história de vida $^{3}$, o que o motivou a apresentar uma filosofia reflexiva, sobretudo de

\footnotetext{
${ }^{3}$ Hans Jonas (1903 - 1993) Filho de Judeu, nascido na Alemanha, viveu grande parte de sua vida observando as mudanças na sociedade durante o século XX, como as guerras mundiais, o Nazismo e as bombas atômicas. Foi em busca da Filosofia motivado pela fama de Husserl, o que o levou estudar em Freiburg. Nesse período, em 1921, participou de seminários oferecidos por Heidegger, que posteriormente seria seu mestre. Como tinha
} 
preocupação. Isso lhe deu o crédito de ser um dos principais pensadores sobre as problemáticas surgidas no contexto do século vinte.

O contexto a que nos referimos é o cenário pós-segunda guerra mundial, sobretudo seus efeitos, e a era da tecnicidade. Entre os pontos observados por Hans Jonas, destaca-se o problema da ameaça do futuro da humanidade. A bomba atômica se torna o grande marco dessa ameaça, pois, a partir dela, tem-se a real noção do ponto a que chegou a humanidade no que tange à ciência, a ponto de produzir algo que possa ser motivo da sua própria extinção. Além da autodestruição da raça humana, essa técnica é também capaz de promover a destruição da vida como um todo. Percebe-se, na sua filosofia, que a exploração da natureza e o progresso tecnológico estão causando um esgotamento progressivo dos recursos naturais, o que pode gerar um colapso ecológico.

Nesse contexto, surge o homem moderno, apontado por Hans Jonas como um sujeito enfraquecido e isolado, individualista e narcisista, que visa unicamente ao domínio e ao lucro. Com as revoluções industriais e técnicas, esse ser moderno tem em si o poder de destruir tudo à sua volta.

É a partir desse cenário que Hans Jonas apresenta o argumento de que "Novos tempos exigem uma nova Ética". Se toda a ação coletiva do Homem está unicamente provocando alterações catastróficas na natureza, torna-se urgente uma revisão do conceito de ética a partir, justamente, do coletivo e não mais do indivíduo, como até então a ética pregava.

A filosofia de Jonas apresenta orientações sobre a importância de recuperarmos o verdadeiro sentido do homem na natureza, em um sentido de presença, de pertença a ela e não de dominador e/ou conquistador. Em sua principal obra, $O$ Princípio Responsabilidade: ensaios para a civilização tecnológica, apresenta a relação entre ética e técnica, a alteração da natureza por mãos humanas e estabelece o sentido da responsabilidade humana frente à sua "vocação tecnológica" e os padrões éticos dela resultantes. De acordo com Oliveira e Sganzerla (2009, p. 263), a grande obra de Hans Jonas tem o objetivo de "dirigir o seu olhar para a importância do conceito de responsabilidade no mundo contemporâneo, uma vez que a ideia de progresso passa a se contrapor ao fato de que o futuro está em perigo". Sob o princípio da responsabilidade coletiva, em que visa não só a vida do homem hoje, mas das gerações futuras, o autor acredita que

fortemente presente em si a questão da religião, decide ainda nesse ano mudar se para Berlin, matriculando-se em duas escolas simultaneamente, dentre as quais se destaca a Escola Superior de Ciências do Judaísmo. A década subsequente é marcada pelos inúmeros estudos, lugares e pessoas com quem Hans Jonas teve contato, em toda a Europa. Até a etapa de seu doutorado, destaca-se o contato com diversos filósofos e pensadores em geral, como Hannah Arendt, Hans-Georg Gadamer, Rudolf Buktmann, Leo Strauss, Martin Buber, entre outros. Nos anos de 40 a 45 Hans Jonas foi soldado na brigada judia pelo exército britânico. Após a segunda guerra mundial, muda-se para a América do Norte, como professor visitante em diferentes universidades dos EUA e do Canadá. Hans Jonas apresenta uma vasta bibliografia, o que lhe conferiu centenas de condecorações, prêmios e títulos Honoris causa. 
devemos, com urgência, reformular o modo como pensamos. Além disso, apresenta a heurística do temor e coloca o medo, não de forma pessimista, mas de forma reflexiva, como meio para refletir acerca das ameaças a que estamos sujeitos.

Para tanto, pretende-se, a partir deste artigo, apresentar uma relação entre ética e técnica. Investigar, num primeiro momento, as principais características e limites da ética tradicional diante dos novos problemas emergentes na sociedade contemporânea. Serão apresentados, também, argumentos acerca da técnica, sua especificação, influência e imposição no atual contexto sociocultural. Como antídoto diante da problemática da técnica, será abordado, de acordo com a filosofia de Hans Jonas, o conceito da heurística do medo, por meio do temor, na qual se procurará encarar o problema da técnica moderna e dos seus reais riscos. Finalmente, pela conscientização acerca do uso da técnica, pautado em princípios de responsabilidade, diante de um progresso científico sem volta, apresentamos a ética jonasiana, que visa não somente ao próprio bem ou ao bem daqueles que convivem com o autor da ação, mas também o bem e a possibilidade da existência de uma vida futura.

\section{Características e limites da ética tradicional}

Por meio da potencialização do sujeito pela técnica, surge, consequentemente, por parte do Homem, um novo comportamento. Esse novo comportamento requer um novo método, e é essa a grande questão a ser refletida, segundo Jonas. Para ele, a técnica se torna uma ameaça, pois a sabedoria humana não acompanha sua evolução, e, infelizmente, o que se percebe é uma violação da natureza concomitante ao que se denomina evolução das civilizações. O homem passa a ser o criador da sua vida humana, criando suas próprias leis, baseadas na sua necessidade e vontade, sempre acreditando estar certo, desde que aja de acordo com aquilo que acredita ser moral. Não há mais o impossível, pois, diante da técnica, tudo se torna possível, a não ser a imortalidade, que ainda amedronta o homem, que não mede esforços para descobrir um meio de se tornar eterno, usando, é claro, dos recursos da técnica.

A reflexão que Hans Jonas propõe é acerca dos valores do passado, que já não atendem aos novos valores que virão à tona no futuro. "Naturalmente, o amanhã só podemos investigar a partir de seus inícios, das tendências legíveis de hoje com mais ou menos probabilidade" (JONAS, 2013, p. 63).

Conforme Oliveira e Sganzerla (2009, p. 263), "na perspectiva tradicional (como a de Kant, Descartes e Aristóteles, segundo Jonas) a ação ética está limitada à relação do homem com o homem, e todas as alterações de domínios se davam no âmbito humano do presente". Diante disso, vale ressaltar em que consistem as éticas tradicionais, quais suas características e limitações. 
Para Kant, a moralidade consiste no agir das pessoas, visando aos direitos humanos. Para ele, a vida humana é um bem inviolável, e o fundamento da moralidade reside na liberdade, num pensamento Libertário. Kant, por meio de sua filosofia, não nega que é errado tentar satisfazer nossas preferências, contudo isso nega nosso agir libertário, pois agimos de acordo com uma força exterior. No mundo exterior, o ser humano expõe-se a desejos, vontades, interesses, porém isso implica fazer escolhas. Nesse contexto, Kant argumenta que as escolhas devem ser feitas pela interioridade, para tornarem-se, assim, autônomas, marcadas pelas escolhas baseadas apenas no princípio da racionalidade. Surge, a partir desse pressuposto, a ideia do Dever como imperativo categórico, na qual a ação moral é aquela realizada com base no dever, derivada de uma ação autônoma. O dever é algo tão grandioso que ele por si só deveria nos motivar a agir conforme ele próprio. O imperativo categórico kantiano está preocupado com a ação atual do indivíduo. "Não há registro na moral de Kant de deveres a serem cumpridos aos membros de gerações futuras ou de uma obrigação por parte dos humanos para com a natureza não-humana" (HECK, 2010, p. 20). Assim, Kant está preocupado com uma coerência do indivíduo consigo mesmo, que se limita somente a si e ao seu tempo, sem "abrir fronteiras" para o próximo.

Para Descartes, a moralidade pressupõe um conhecimento integral com outras ciências, pois a moral consiste, justamente, no último grau da sabedoria. Assim, argumenta que é impossível formar uma moral definitiva. Por meio do que ele denomina Moral Provisória, procura estabelecer um código moral temporário, direcionando as ações humanas. A moral provisória apresenta-se como uma etapa temporária, enquanto ele põe em prática o seu método, que consiste na dúvida diante de tudo, visando buscar a verdade. Essa etapa é necessária, segundo Descartes, a fim de se chegar à verdadeira ciência. Para ele, o caminho para uma vida moral consiste em seguir as leis e os costumes para estabelecer uma vida sensata e moderada com o presente e com a realidade que circunda o ser.

Aristóteles, filósofo que deu uma significativa importância ao tema da ética, enfatiza que o caráter virtuoso é o critério fundamental para a concretização da felicidade. Segundo a sua teoria, a ética está fundamentada na pólis. Aristóteles parte do pressuposto que devemos viver para desenvolver as nossas aptidões a fim de colocá-las à disposição desta. A ética nasce, nesse contexto, do ventre da pólis, na qual o ser humano só alcançará a felicidade vivendo em harmonia com os outros e promovendo o bem comum da Sociedade. A ciência ética, para Aristóteles, está intimamente associada à ciência política, pois determinam quais são as demais ciências que devem ser estudadas, e isso se torna imprescindível para o bom convívio e para o bom andamento da cidade. Assim, a conscientização ética passa a ser critério essencial para a formação do caráter, e é mediante as práticas sociais e o momento no qual o Homem está 
inserido, por ações dignas de virtude, que haverá discernimento para fazer o que for certo, e isso trará a felicidade e promoverá a virtude.

Frente às diferentes teorias éticas brevemente apresentadas, percebese que todas têm um caráter eminentemente antropológico e de ação imediata - a ética sempre esteve preocupada em estabelecer as relações entre os sujeitos. Isso se percebe em toda teorização ética ao longo da história da humanidade. Esses aspectos, para Jonas, se tornam um limite por se preocuparem unicamente com essa relação antropocêntrica e continuar ignorando a relação homem-natureza.

\begin{abstract}
[...] Se antes tudo o que fosse não humano não deveria ser objeto da ética, pois esta consistia num reflexo antropocêntrico que tratava o homem em sua essência (e não como objeto de sua própria ação) e todo o pensamento ético estava reduzido ao tempo presente, pois toda ação era medida a partir de um raio limitado de alcance imediato, então à ética não se exigia nenhuma consideração sobre a existência da própria humanidade e sequer uma consciência sobre a vulnerabilidade da natureza frente ao poder de intervenção do homem. Na sociedade tecnocientífica, todavia, é preciso incluir à ação de agora o pensamento sobre a condição de integridade da humanidade como um todo no futuro (OLIVEIRA; SGANZERLA, 2009, p. 265).
\end{abstract}

Os mais diferentes limites da ética tradicional são abordados por Hans Jonas em sua principal obra, como limitadores de uma ética que precisa ser repensada e reelaborada. Aponta, nesse sentido, que todas as máximas, até então, apresentavam a ética nessa ideia, nessa relação do homem consigo mesmo ou com seu semelhante. São exemplos: "Ama a teu próximo como a ti mesmo", "Instrui teu filho no caminho da verdade", "Nunca trate teus semelhantes como simples meios, mas sempre como fins em si mesmo", "Submete o teu bem pessoal ao bem comum" (JONAS, 2006, p. 36).

Pautado o agir ético nessas máximas, obtinha-se uma resposta quase sempre imediata. As consequências, por outro lado, ficavam ao acaso. "Em todas essas máximas, aquele que age e o 'outro' de seu agir são partícipes de um presente comum. Os que vivem agora e os que de alguma forma têm trânsito comigo são os que têm alguma reivindicação sobre minha conduta, na medida em que esta os afete pelo fazer ou pelo omitir" (JONAS, 2006, p. 36). Em resumo, pode-se afirmar que a ação sobre objetos não humanos não se caracterizava como um agir ético, independentemente da intenção da qual esse agir era motivado.

Hans Jonas, ao argumentar sobre a ética tradicional, não poupa pontos que precisam ser revistos, e estes são apontados inúmeras vezes na sua principal obra:

O bem e o mal, com o qual o agir tinha de se preocupar, evidenciavam-se na ação, seja na própria práxis ou em seu 
alcance imediato, e não requeriam um alcance imediato, e não requeriam um planejamento a longo prazo. [...] $\mathrm{O}$ alcance efetivo da ação era pequeno, o intervalo de tempo para previsão, definição de objetivo e imputabilidade era curto, e limitado o controle sobre as circunstâncias. O comportamento correto possuía seus critérios imediatos e sua consecução quase imediata (JONAS, 2006, p.35).

A curta aplicabilidade dessa ética no tempo e no espaço é também uma clara crítica apresentada por Jonas. Avalia-se o bem e o mal da ação somente sob o critério do presente. Nega-se, a partir desse pressuposto, avaliar a condição global da vida humana, a vida das gerações futuras bem como das demais espécies e do próprio planeta. O futuro não é critério de avaliação na ética tradicional, e este se torna um grande limite, segundo Jonas, pois está sujeito, perante a ética, ao acaso. E, infelizmente, se o modo de pensar acerca de como usamos, maltratamos e destruímos as coisas na natureza não sofrer nenhuma ação moral maior, ou seja, se não houver uma mudança no pensamento ético, que seja voltada para a preservação e o cuidado, o caminho, infelizmente, será aquele temido por Jonas.

\section{A questão da técnica}

Para compreender a problemática da técnica em Hans Jonas, é necessário compreender o nascimento dessa técnica, que visava justamente à conquista da natureza, por meio do ideal moderno, sobretudo com a teoria de Bacon "saber é poder", bem como o pensamento acerca da temática de seu mestre, Heidegger, do qual Jonas extrai suas principais ideias no que tange ao referido assunto.

Ao esboçar alguns escritos acerca da técnica, Heidegger afirma que é necessário analisar separadamente a técnica da questão da técnica. Apresenta uma distinção entre a técnica em si, como uma simples operação ou um simples agir, algo que acontece ou deixa de acontecer; da técnica como uma reflexão, algo que tange à filosofia e à reflexão humana, visando extrair desta à essência. Alerta que, se no percurso humano não houver nenhuma alteração, seu caminho será a maquinação, pois a técnica se tornará a estrutura de uma nova ordem humana que poderá levar à extinção da humanidade. A ideologia da técnica como algo neutro conferiu ao homem o poder de transformá-la como algo para o bem ou para o mal.

Por todos os lados, permaneceremos, sem liberdade, atados a ela, mesmo que a neguemos ou a confirmemos apaixonadamente. Mas de modo mais triste estamos entregues à técnica quando a consideramos como algo neutro; pois essa representação, à qual hoje em dia especialmente se adora prestar homenagem, nos torna completamente cegos perante a essência da técnica (HEIDEGGER, 2007, p. 376). 
Segundo o mestre de Jonas, estamos comprometidos com a era tecnológica, e somos desafiados a vencer os obstáculos que ela nos apresenta. Por meio de sua ontologia, Heidegger apresenta a técnica como uma revelação da existência, que é formada em cada época, influenciada pelo meio. Se estivermos deixando de lado o pensar reflexivo, é porque o pensamento calculador e a técnica tomaram conta. De acordo com Possamai (2010, p. 23), ao falar da técnica em Heidegger, "o que caracteriza nossa era é a dominação da técnica moderna, presente em todas as esferas da vida. Representam essa dominação a funcionalização, a perfeição, a automatização, a burocratização e a informação. A técnica está em estreita relação com o ser, e acaba por determinar, dessa forma, a humanidade".

Contudo, a preocupação de Heidegger não consiste na técnica em si, mas no fato de estarmos esquecendo cada vez mais o nosso ser. A técnica moderna se faz presente em todo cotidiano da vida. Está numa relação constante com o ser, e sua ameaça consiste em transformar também o homem em objeto. A tecnologia moderna se torna a metafísica da nossa época. É por ela que se estabelece a relação com as coisas da nossa época. Nesse sentido, afirmar que vivemos a era da tecnologia moderna implica supor que a tecnologia constitui a época moderna, ou seja, é uma característica sua. A maquinação está moldando o sujeito e transformando-o em um objeto manipulável. Assim, o próprio homem tem-se tornado objeto e sujeito do seu consumo. Nesse sentido, Heidegger vem afirmar que o caminho que a técnica está tomando não vem apresentar nada de técnico, mas é a condição humana que está em jogo e está conferindo um poder à técnica que não lhe compete.

Heidegger acredita que a técnica em si não se caracteriza como uma aplicação da ciência moderna, pois ela sempre existiu e sempre existirá enquanto houver humanidade. Ela é um modo de conhecer, de desabrigar. Segundo o próprio Heidegger (2007, p. 380), "a técnica desabriga o que não se produz sozinho e ainda não está à frente e que, por isso, pode aparecer e ser notado, ora dessa, ora daquela maneira". A técnica surge como a necessidade que precisa ser imposta à razão.

A problemática notória da técnica moderna, a partir disso, é a sua imposição. É característica imanente procurar acelerar os ciclos naturais, visando à produção, aos fins, aos resultados. Um rio, perante a técnica, pode muito mais do que dar de beber aos animais, ou correr tranquilamente pelo seu leito. Ele pode produzir energia. A natureza não é mais vista como natureza em si, e sim como reserva, como matéria prima, um depósito caseiro de reservas e energias. Criou-se, nessa era da tecnicidade, a cultura de pensar a natureza como algo que está sempre disponível a nos oferecer algo.

Diante disse, Heidegger propõe uma reflexão a respeito da nossa real pertença ao meio. Pelo fato de estarmos tão reféns da técnica moderna, conseguimos realmente fazer a experiência da natureza, além do simples turismo? Compreendemos a natureza quando nos envolvemos e nos 
preocupamos com ela. É necessário refletirmos acerca disso, pois todos os interessados estão envolvidos por essa tecnologia. Estamos fascinados e não olhamos mais em volta. É um atacar revelador constante à natureza. E isso só tende a aumentar a ponto de exigirmos da natureza mais do que ela pode nos dar. Extrair se torna a regra da sociedade contemporânea, seja nós da natureza, seja o gestor do trabalhador, e assim sucessivamente, a fim de garantirmos estoque. Nessa relação, a natureza é a fonte de energia e nós, meios para a produção dessa energia.

A técnica se tornou muito mais do que um meio. É um modo por meio do qual acontece o desabrigar-se. Desde o período antigo, com os gregos, por exemplo, a técnica desempenhava essa função, contudo a "técnica moderna é algo totalmente incomparável com todas as outras técnicas anteriores, porque ela repousa sobre a moderna ciência exata da natureza" (HEIDEGGER, 2007, p. 381). Assim, palavras como transformar, armazenar e distribuir são imperativos que regem a técnica moderna, pois esta conferiu ao ser humano a capacidade de conquistar aquilo que nunca antes fora imaginado.

A partir disso, Heidegger procura apresentar a essência da técnica, que, segundo ele, não apresenta nada de técnico, pois aquilo que chamamos de técnica já é uma representação.

A técnica não deve, pois, ser vista como uma aplicação eventual da ciência; à natureza como complexo de forças passível de ser calculado corresponde a disponibilidade do ente para a dominação e a utilização. Dizer, pois, que a técnica já está posta no próprio núcleo essencial da ciência moderna é um passo a mais na direção da compreensão da essência da técnica, porque essa conjunção corresponde a um apelo da época, que o homem deve atender e através do qual visa justificar a sua posição histórica. O modo peculiar de desabrigamento que está envolvido na técnica moderna corresponde ao destino que o homem deve cumprir (SILVA, 2007, p. 371).

Nesse intuito, Heidegger afirma que conhecer a técnica em sua essência consiste em conhecer a disponibilidade que cada ser possui, ou seja, o modo particular que cada um experimenta e deixa se experimentar por ela. Os escritos de Heidegger não consistem num julgamento da técnica, mas, sim, na ideia de compreensão dela. A técnica é algo que se apresenta ao homem, e cabe a este ser racional cumpri-la "O homem não é o senhor da técnica, mas pode ser o senhor da sua relação com a técnica" (SILVA, 2007, p. 373).

\section{Heurística do temor: técnica versus ética do futuro}

Com o advento da modernidade, o sujeito passa a ser a fonte do conhecimento moral e atua com domínio sobre a natureza, pois, nesse sentido, cabe somente ao Homem ser portador de um fim em si mesmo. 
Esse contexto faz uma ruptura no modo de pensar, entre o medievo e o moderno, o que gera a potencialização do sujeito e, consequentemente, a desvalorização da natureza. As consequências que surgem a partir dessa sociedade são os mais variados e imagináveis desastres.

Ao observar o rumo que a sociedade técnica estava tomando, Jonas percebe que as consequências desastrosas, oriundas do imenso poder que o ser humano adquiriu sobre a natureza, necessitavam de uma responsabilidade mais reflexiva por parte do Homem, para ele mesmo não ser causa da sua própria extinção. A ação humana ultrapassou os limites a ponto de uma intervenção biotecnológica, por exemplo, causar efeitos em diversas gerações subsequentes. Nas palavras de Jonas, tal efeito é denominado "escravidão do homem futuro pelo homem presente".

Segundo o autor, a grande questão a ser analisada, ao se falar da técnica, é que esta, infelizmente, está interferindo no todo da vida humana, como viver e morrer, desejos, ações, pensamentos. Aponta, inclusive, a possibilidade de uma Filosofia da Tecnologia.

[...] Sua preocupação indica o quanto é inquietante e delicada a situação de uma sociedade que, progressivamente, estabelece o critério para avaliar o grau de seu desenvolvimento, a partir dos avanços da ciência e da tecnologia. [...] Jonas enfatiza que a técnica em muito extrapolou seu sentido meramente instrumental (SANTOS, 2009, p. 280).

A crítica de Hans Jonas à técnica moderna está relacionada aos fins extrativistas e capitalistas que ela adotou. A exploração causa o esgotamento progressivo dos recursos naturais, o que gera um colapso ecológico. Foi por meio do egoísmo exagerado que houve a depredação da natureza, a ponto de tirar dela o que ela já não poderia mais oferecer.

Sendo uma capacidade humana, não podemos, porém, considerar a técnica como algo ruim ou mau. Conforme escreve Viana (2010, p. 110), “a técnica moderna representa uma nova "caixa de Pandora" de onde saem seja gift (em inglês: presente), seja gift (em alemão: veneno), constituindose uma ameaça para a humanidade".

Como faculdade cognitiva humana, a técnica é boa. É essa também a concepção do próprio Hans Jonas. O que é ruim é o uso, a forma como empregamos essa técnica, donde surgem consequências negativas para a

\footnotetext{
${ }^{4}$ Caixa de Pandora é um mito grego que narra a chegada da primeira mulher à Terra, e com ela a origem de todas as tragédias humanas. Pandora é uma mulher, que é enviada por Zeus a Prometeu, juntamente com uma caixa, que jamais deveria ser aberta, pois dentro continha todos os males possíveis para a humanidade, como guerras, discórdias, doenças. Zeus enviara a mulher e a caixa com o intuito de se vingar de Prometeu, uma vez que este deu a humanidade o poder do domínio do fogo, contrariando as ordens do deus grego. Não se contendo com a curiosidade, Pandora abre a caixa, liberando assim, todos os males a sociedade.
} 
humanidade. O progresso é importante, mas é necessário refletir sobre o que há por trás dele.

Nesse sentido, não podemos considerar a opinião de Jonas como pessimista, mas o fato concreto é que a tecnologia moderna gerou uma possibilidade de ameaça à humanidade. Neste novo cenário no qual se encontra a humanidade, no entender de Jonas, o que deve ser temido é o "sucesso" da técnica e não o seu "fracasso", pois o que está em jogo no "sucesso" é, nada mais e nada menos, do que o futuro da humanidade. Os efeitos da bomba atômica sobre as cidades japonesas, por exemplo, são frutos de experimentos técnicos que deram certo, e os efeitos, sabemos quais foram. Nesse contexto, Jonas assim se expressa:

[...] a probabilidade de que experimentos desconhecidos tenham um resultado feliz ou infeliz é, em geral, semelhante aquela em que se pode errar ou acertar o alvo: o acerto é apenas uma entre tantas alternativas, que na maior parte dos casos passam, aliás, de tentativas fracassadas [...] A evolução trabalha com pequenos detalhes. Nunca arrisca um tudo ou nada (2006, p. 77).

Uma grande problemática que surge a partir dessa técnica é que a tecnologia avança a passos muito acelerados, enquanto que a natureza em seu percurso normal, desde sempre foi lenta, levando centenas, até milhares de anos para apresentar alguma mudança significativa. Jonas argumenta que apostar a vida de toda uma sociedade pelo sucesso da técnica é muito perigoso e pode significar a extinção dessa sociedade.

A partir dessas premissas, Hans Jonas apresenta aquilo que ele denomina de heurística do temor. Diariamente, tomamos conhecimento de guerras, catástrofes naturais e novas invenções científicas que nos colocam em perigo e que, muito pouco, para não dizer nada, mudam nossa maneira de pensar e agir frente a essas ameaças. Por meio da heurística, Jonas procura apresentar o medo com um fim que pode gerar um efeito positivo. Constata que, enquanto humanos, damos valor a algo quando o perdemos, quando não o possuímos mais. Sabemos o que é liberdade, quando sentimos a sua falta, seja em um leito de hospital ou na prisão. Cuidamos de nossa saúde quando estamos acometidos de uma doença. Damos valor ao nosso capital, quando não o possuímos mais.

Surge, a partir dessa exemplificação, um conflito perceptível entre o bem e o mal. O reconhecimento do mal sempre é mais perceptível do que seu antônimo. "O mal nos impõe sua simples presença, enquanto que o bem pode ficar discretamente ali e ficar desconhecido" (JONAS, 2006, p. 71). Ainda segundo Jonas, "não duvidamos do mal quando com ele deparamos; mas só temos certeza do bem quando dele nos desviamos".

A partir dessa certeza que temos do mal que queremos evitar, Hans Jonas propõe delimitarmos nosso agir. "Sabemos muito bem o que queremos que não nos aconteça, ou, abreviadamente, temos consciência imediata sobre o que não queremos". "O mal imaginado como 
consequência de nossas opções e ações (no futuro) deveria servir de contraponto ao agir concreto aqui e agora" (SANTOS, 2009, p. 286).

Por meio desse "alarme" da heurística do medo, como muitos o interpretaram, Jonas procura colocar o temor como uma simples justificação do medo, ou seja, busca despertar a reflexão das pessoas por meio de um sentimento. Para incitar as pessoas a escolherem o melhor caminho para elas mesmas, ele propõe refletirem sobre as ameaças a que estão sujeitas. O medo tem aqui o objetivo de aprendizado.

\begin{abstract}
Precisamos da ameaça à imagem humana - e de tipos de ameaça bem determinados - para, com o pavor gerado, afirmamos uma imagem humana autêntica. Enquanto o perigo for desconhecido não se saberá o que há para proteger e por que devemos fazê-lo: por isso, contrariando toda lógica e método, o saber se origina daquilo contra o que devemos nos proteger (JONAS, 2006, p. 71).
\end{abstract}

O temor, como proposta de sensibilização, visa preparar o homem para o desconhecido, sobretudo num sentido de reflexão acerca do qual esse ser está sujeito. Por meio da heurística do temor, Jonas propõe seu método analítico, necessário para a busca do bem ou, em outras palavras, para a continuidade da vida como um todo. $\mathrm{O}$ medo torna-se uma virtude no contexto, cuja característica é a Sabedoria, apresentado por Jonas. Devemos temer a incerteza da natureza ou da nossa ação sobre ela, e se assim mudarmos nossas ações, visando o bem comum, estaremos sendo sábios.

\title{
Ética da responsabilidade e progresso científico
}

Frente ao cenário anteriormente apresentado, Hans Jonas percebe a necessidade de apresentar uma nova proposta, com o intuito de garantir a vida. O termo responsabilidade está diretamente relacionado a essa nova ideia de agir. "O agente deve responder por seus atos: ele é responsável por suas consequências e responderá por elas, se for o caso" (JONAS, 2006, p. 165). Termos como negligência estão diretamente associados à irresponsabilidade e devem ser extintos do vocabulário desse novo agir ético.

Cabe às gerações que convivem no cenário da era da tecnicidade, tornar possível a continuidade da vida e, consequentemente, a sobrevivência das gerações futuras, pautando as suas ações em um agir responsável. O ponto de saída proposto é estabelecer uma revisão dos patamares éticos, pois se percebe que, partindo somente do indivíduo, os danos que estão sendo causados à natureza estão sendo somente maléficos. Urge uma descentralização do sujeito, por meio do "reducionismo antropocêntrico, que nos destaca e nos diferencia de toda a natureza restante, o que significa apenas reduzir e desumanizar o homem, com o objetivo expresso de preservação e de dignidade do seu Ser" (JONAS, 2006, p. 229). Assim, é necessário que seja desenvolvida uma ética extra-humana, que vise não 
somente ao bem-estar do homem contemporâneo, mas também das gerações futuras, as vidas que ainda não existem, e a natureza em que esse ser habita.

Por meio do desenvolvimento do princípio responsabilidade, o futuro se torna um dos principais objetos da ética. Inova, pois o futuro é algo desconhecido, algo que ainda não é, mas que virá a ser se não for extinto antes. Contudo "a ética jonasiana do futuro não pretende substituir as doutrinas éticas usuais. Trata-se, a rigor, tão-só de complementar as diversas éticas tradicionais para atender ao novo desafio do superdimensionamento da civilização tecnológica" (HECK, 2010, p. 22). Na ética tradicional, o futuro mais distante, analisado por ela, estende-se somente até a próxima geração, visando preparar uma continuidade, uma forma de garantia de dominação, de posses e poder. Segundo Jonas, "as futuras gerações eram uma repetição daquelas primeiras, que viveriam sempre na mesma casa, com os mesmos fundamentos" (JONAS, 2006, p. 209).

Por meio desse princípio, Jonas visa apresentar o futuro como condição de possibilidade e continuidade, um "lugar" onde se repercutirão as ações humanas. Inclui, nessa projeção para o futuro, não apenas a vida humana, mas a vida como um todo, dos demais seres, do planeta, tornando esse princípio extra-humano, pois ousa ampliar os horizontes sobre os quais procura refletir. O futuro da humanidade é a primeira obrigação do comportamento coletivo humano na idade da civilização técnica.

Essa nova ética, a partir da premissa do futuro, visa promover o papel inverso a aquele surgido com a teoria Baconiana, não mais promovendo a potencialização do Sujeito, mas sua descentralização e a exaltação da natureza.

[...] A união do poder com a razão traz consigo a responsabilidade, fato que sempre se compreendeu, quando se tratava da esfera das relações intersubjetivas. O que não se compreendera é a nova expansão da responsabilidade sobre a biosfera e a sobrevivência da humanidade, que decorre simplesmente da extensão do poder sobre as coisas e do fato de que este seja, sobretudo, um poder destrutivo (JONAS, 2006, p. 231).

Considerando todo o contexto da ética tradicional e da era da técnica, Jonas propõe um novo imperativo ${ }^{5}$ para a ética. Apresenta a ideia de que "devemos agir a modo que os efeitos de nossa ação não sejam destrutivos da possibilidade de uma vida futura" ou que "Não devemos colocar em perigo as condições de sobrevivência indefinida da humanidade sobre a Terra". Essa reformulação do imperativo Kantiano reflete uma nova maneira de pensar, não mais preocupada consigo mesmo, mas com os

${ }^{5} \mathrm{O}$ imperativo a que Hans Jonas propõe reformular é o imperativo categórico de Immanuel Kant, que afirmava que devemos agir de modo que queiramos que nossa ação se torne uma lei universal. A razão deve existir de modo que possa ser concebida sem contradição. 
efeitos gerais que a nossa ação poderá causar. A partir desse pressuposto, o válido é que não só a vida do Homem do presente está assegurada, mas também a do Homem no futuro, a vida das demais espécies e a do próprio planeta. Antes se pregava que não se deveria matar. Agora, a premissa que passa a ter peso é a ideia de que não se deve destruir, pois o homem, infelizmente, adquiriu esse poder.

Segundo Jonas, o que importa, no atual contexto, é refletir e estabelecer uma ética que vise à conservação, pois o progresso está totalmente desenfreado. Sobre o progresso, Hans Jonas se refere aos possíveis progressos passíveis aos homens, desde o caminhar, nas relações sociais ou no caminho escolar. Estamos em constantes progressos, pois o "progresso é a lei de desenvolvimento obrigatório do devir humano, da qual todos têm de participar" (JONAS, 2006, p. 268).

Em todos os processos, ao falarmos de progresso, sempre procuramos estabelecer um avanço, procuramos algo que consideramos ser melhor. Contudo o caminho que o progresso tecnológico está tomando está marcado mais pela arrogância e pelo interesse do que pela real necessidade, gerando, assim, a impressão de que os ganhos são menores do que as perdas, ou seja, não "vale a pena". Os poderes e os efeitos sobre a natureza, por exemplo, fazem com que ela não consiga mais atingir a demanda mundial. Mesmo se houvesse uma redistribuição dos recursos naturais e da riqueza global, provavelmente isso não aconteceria de forma pacífica e não seria suficiente para elevar o nível de vida das regiões mais pobres.

Conforme Zancanaro,

As utopias racionalistas, os mitos e a religião foram substituídos pelo dinamismo tópico do progresso tecnológico, alterando as formas de representação e produzindo um vazio ético. O homem serviu-se da ciência a suas forças, agora necessita frear seus poderes ilimitados. Aqui está radicado o poder ético (1998, p. 72).

Essa crítica, levantada por Jonas e por seus seguidores, acerca do progresso científico, visa unicamente a uma coisa: a garantia da sobrevivência da vida humana e extra-humana. Para Heck (2010, p. 32), o caráter jonasiano de responsabilidade "resulta da falta de limites que caracterizam a dinâmica do progresso, o qual aparentemente se move em direção ao fim do gênero humano, levado por uma incontrolável superposição de riscos mundo afora". O antídoto, mediante esse progresso desenfreado, é o princípio da responsabilidade, que se apresenta como uma relação não recíproca, ou seja, é uma relação de cuidado simplesmente pelo fato do cuidar, de se importar com o desconhecido, com os outros, com a natureza e com o futuro. A responsabilidade aqui descrita não significa diminuir o progresso, mas que este seja alcançado com ações responsáveis e com preocupação voltada para a continuidade da vida. 


\section{Considerações finais}

Por meio da filosofia reflexiva, Jonas procura apresentar um diagnóstico do atual momento em que estamos vivendo. Mesmo sendo escrito no século XX, O Princípio Responsabilidade: ensaios para a civilização tecnológica, continua atualizado, digno de inúmeras leituras, artigos, debates e reflexões. A relativização dos valores morais, diante de uma técnica que se impõe, precisa ser revista, e o homem precisa sair do centro de toda e qualquer discussão moral.

A ética que Hans Jonas propõe não está pautada na felicidade, como sugere Aristóteles, ou em uma moral provisória, segundo a tese de Descartes, nem na liberdade, argumento de Kant, mas numa resposta prática para a resolução de problemas que se tornaram reais, como a existência da vida em todos os aspectos. Jonas não se preocupou em apresentar uma proposta política concreta para colocar em prática o seu princípio, mas, em resumo, sua tese consiste no cuidado, na preservação e na conservação daquilo que deverá garantir a continuidade da vida. Não apresenta uma solução plausível diante de cada situação prática, mas é diante do medo (heurística do temor) que procura convencer o leitor a tomar o cuidado para evitar aquilo que não quer que aconteça, nem a si, nem aos demais seres da natureza. "O Princípio Responsabilidade não é progressista e/ou revolucionário senão conservador e cético - em suma, zela pela heurística do medo à procura da fuga de uma ameaça definitiva" (HECK, 2010, p. 32). A busca do bem, para Jonas, consiste, portanto, no mal a ser evitado. Ao não permitir que o mal prevaleça, o bem se fará presente, mesmo que for de forma sutil.

O parecer de Jonas está voltado para uma mudança de cultura que se instaurou na era da tecnicidade. Estamos intimamente ligados à técnica e não nos imaginamos mais sem ela, e isso acontece no simples levantar, pelo alarme do relógio, até o prolongamento da vida, por meio de aparelhos de última geração de um hospital. Contudo, essa cultura precisa ser revista. Os recursos tecnológicos são importantes e necessários, estão para servir o homem, mas não podem prendê-lo. Essa desculturalização técnica precisa acontecer de forma que nos permita pensarmos e encararmos os recursos tecnológicos como meios, e não como fins em si mesmo. O ensino deve partir desse pressuposto. É necessário apresentar aos discentes, seres humanos que estão formando o seu caráter crítico, uma educação acerca dessa temática e que esteja voltada para um pensar de pertença, de engajamento e envolvimento, não só no meio em que estão inseridos, mas no Planeta Terra como um todo, visando um agir responsável. Esse agir implica participação e denúncia: participação do processo político, envolvimento com ações e propostas dignas que garantam o bem à vida como um todo, sobretudo a continuidade; e denúncia para com aquelas ações que vão contra a vida, muitas vezes camufladas pela ideia do progresso e do bem que este poderia trazer. Pelo fato de estarmos tão 
ligados à técnica, criamos a ilusão de que ela é natural, quando na verdade não é. Os recursos da técnica são meios criados pelo Homem a partir de determinadas necessidades que foram surgindo ao longo da história, e a saída para conviver com eles, portanto, não consiste na fuga, mas no seu uso crítico e ético ou, segundo Jonas, num uso responsável. 


\section{Referências bibliográficas}

FONSECA. L. S. G. Liberdade da necessidade ou a resolução do dualismo segundo Jonas. In: Dissertatio, UFPel [32, 2010] 55 - 75.

HECK. J. N. O princípio responsabilidade Hans Jonas e a teleologia objetiva dos valores. In: Dissertatio, UFPel [32, 2010] 17- 35.

HEIDEGGER, M. A questão da Técnica. In: ScienticeStudia, São Paulo, 2007, v. 5, n. 3, p. 375-398;

JONAS, H. $O$ princípio responsabilidade: ensaio de uma ética para a civilização tecnológica. Rio de Janeiro, RJ: Contraponto, 2006.

JONAS, H. Técnica Medicina e Ética: sobre a prática do princípio responsabilidade. São Paulo, SP: Paulus, 2013.

NETO, R. R. A. Pensamento e Tecnologia na era moderna. In: Pensando: Revista de Filosofia. V. 1, no 2, 2010. p. 3-16

OLIVEIRA, J. R. A transanimalidade do Homem: uma premissa do princípio responsabilidade. In: Dissertatio, UFPel [32, 2010] 77- 97.

OLIVEIRA, J. R. de; SGANZERLA, A. Jonas, para uma ética da responsabilidade com o futuro. IN: SGANZERLA, A; FALABRETTI, E. S; BOCCA, F. V. (orgs) Ética em movimento. São Paulo, SP: Editora Paulus, 2009. p. 261-270.

PIZZI, J. Jonas e o enaltecimento da Heurística: a reponsabilidade frente ao futuro ameaçado. In: Dissertatio, UFPel [32, 2010] p. 99-117.

POSSAMAI, F. V. A técnica e a questão da técnica em Heidegger. In: Intuitio, Porto Alegre, 2010, v. 3, n. 01 p. 20-32.

SANTOS, R. Ética da responsabilidade e Ética do discurso: as propostas de Hans Jonas e Karl-Otto Apel. In: Dissertatio, UFPel [32, 2010] 139-155.

SANTOS, R. O problema da técnica e a crítica à tradição na ética de Hans Jonas, In: Dissertatio, UFPel [30, 2010] p. 269-291.

SANTOS. M. J. Desafios éticos advindos da efetividade do Binômio ciênciaTécnica. In: Pensando: Revista de Filosofia. V. 1, nº 2, 2010. p. 90-105.

SHIO, S. A ética da responsabilidade em Arent e Jonas. In: Dissertatio, UFPel [32, 2010] 157-174.

SILVA, F. L. Martin Heidegger e a Técnica. In: ScienticeStudia, São Paulo, 2007, v. 5, n. 3, p. 369-74;

VIANA, W. C. A técnica sob o "Princípio Responsabilidade" de Hans Jonas. In: Pensando - Revista de Filosofia. Vol. I, Número 02, 2010.

ZANCANARO, L. O conceito de responsabilidade em Hans Jonas. Tese de doutorado. Universidade Estadual de Campinas, 1998.

ZANCANARO. L. Singularidades dificuldades do Pensamento de Hans Jonas. In: Dissertatio, UFPel [32, 2010] 119-137.

\section{Contribuição dos autores:}

Os autores Marcos Alexandre Alves e Neimir Paulo Mentges problematizaram, discutiram, revisaram e redigiram o artigo. A versão final do texto foi aprovado pelos autores.

Autor(a) para correspondência: Marcos Alexandre Alves, Centro Universitário Franciscano, R. dos Andradas, Centro, CEP 97010-030, Santa Maria - RS, Brasil. maralexalves@gmail.com 